\title{
Universiteit
}

Leiden

The Netherlands

\section{Anxiety sensitivity profile: dimensional structure and relationship with temperament and character}

Does, A.J.W. van der; Duijsens, I.J.; Eurelings-Bontekoe, E.H.M.; Verschuur, M.J.; Spinhoven, P.

\section{Citation}

Does, A. J. W. van der, Duijsens, I. J., Eurelings-Bontekoe, E. H. M., Verschuur, M. J., \& Spinhoven, P. (2003). Anxiety sensitivity profile: dimensional structure and relationship with temperament and character. Psychotherapy And Psychosomatics, 72, 217-222. Retrieved from https://hdl.handle.net/1887/15007

Version: $\quad$ Not Applicable (or Unknown)

License: $\quad$ Leiden University Non-exclusive license

Downloaded from: $\underline{\text { https://hdl.handle.net/1887/15007 }}$

Note: To cite this publication please use the final published version (if applicable). 


\title{
Anxiety Sensitivity Profile: Dimensional Structure and Relationship with Temperament and Character
}

\author{
Willem Van der Does ${ }^{a, b}$ Inge Duijsens ${ }^{a}$ Elisabeth Eurelings-Bontekoe ${ }^{a}$ \\ Margot Verschuura Philip Spinhoven ${ }^{a, b}$
}

Departments of a Psychology and ${ }^{\mathrm{b} P s y c h i a t r y}$, Leiden University, Leiden, The Netherlands

\section{Key Words}

Anxiety sensitivity · Personality · Temperament . Character - Anxiety · Panic disorder · Depression

\begin{abstract}
Background: Anxiety sensitivity (AS), the belief that bodily sensations have harmful consequences, is a reliable predictor of panic attacks in both clinical and nonclinical populations. Recently, a new measure of AS has been proposed. The AS profile (ASP) was designed to be a more comprehensive measure of AS, and to be more suitable for the measurement of different AS dimensions. Preliminary evidence (college student sample) suggests that the ASP has 4 dimensions. In the present study, the dimensional structure of the ASP was further investigated, as well as its relationship with temperament and character traits. Methods: Exploratory and confirmatory factor analysis of ASP scores in two large samples of psychiatric outpatients and nonclinical controls (combined $n=742$ ). Correlations and partial correlations of ASP with temperament and character. Results: Exploratory factor analysis yielded a single AS factor. However, confirmatory factor analysis showed that the 6-dimensional structure, as Taylor and Cox had origi-
\end{abstract}

nally intended it, might be a defendable solution. However, the number of items is much too high, with many subscales consisting of semantic clusters. ASP scores were found to be weakly related to the temperament dimension harm avoidance, corroborating earlier findings that were not statistically significant because of small sample sizes. Conclusions: The ASP may be shortened from 60 to 24 items without loss of reliability or content. Future studies using challenge paradigms and studies with general hospital patients may further investigate the usefulness of a shortened version of the ASP.

Copyright $@ 2003$ S. Karger AG, Basel

Anxiety sensitivity (AS) refers to the fear of bodily sensations, based on the belief that bodily sensations have harmful consequences [1]. AS includes, but is not synonymous with, the tendency to misinterpret bodily sensations catastrophically. For instance, high AS individuals may know perfectly well that certain bodily sensations (e.g. palpitations) are not signs of immediate danger (e.g. impending heart attack). However, they may believe that having these sensations causes damage in the long run. According to Reiss and McNally [1] and McNally [2], AS is a vulnerability factor for the development of panic

\section{KARGER}

Fax +41613061234

E-Mail karger@karger.ch

www.karger.com (c) 2003 S. Karger AG, Basel

$0033-3190 / 03 / 0724-0217 \$ 19.50 / 0$

Accessible online at:

www. karger.com/pp
Dr. A.J.W. Van der Does

Department of Psychology, Leiden University

Wassenaarseweg 52

NL-2333 AK Leiden (The Netherlands)

Tel. +31715273377, Fax +31715274678, E-Mail vanderdoes@fsw.leidenuniv.nl 
attacks, not a consequence of or conditioned response to panic attacks or intense bodily sensations. This implies that AS can also be measured in individuals who have never experienced panic attacks.

The most widely used instrument to assess AS is the 16-item Anxiety Sensitivity Index (ASI) [3]. The ASI has been shown to produce reliable scores, and to differentiate between panic disorder patients and patients with other psychiatric disorders (including anxiety disorders) [4]. Furthermore, ASI scores predict the occurrence of panic attacks in healthy individuals during a highly stressful period $[5,6]$.

The question of whether AS is uni- or multidimensional has been controversial [7, 8]. This question is important because if AS is in fact multidimensional, relationships between a global measure of AS and other variables may be obscured. For instance, the relationship between AS and response to $\mathrm{CO}_{2}$ challenge may be less strong than the relationship between a (postulated) AS dimension 'suffocation fear' and response to $\mathrm{CO}_{2}$. Research findings in this area seemed to be inconsistent, with about an equal number of studies supporting the uni- and multidimensional view. However, it has been shown that a hierarchical model of AS (as measured by the ASI), consisting of 3 partially distinct first-order factors and 1 general secondorder factor, resolves these inconsistencies [9]. The 3 firstorder factors are: physical concerns; mental incapacitation concerns, and social concerns [9]. However, the results of factor analysis depend heavily on the comprehensiveness of the measurements. The ASI has only 16 items, and may be too short to reliably assess separate dimensions of AS [10]. On the other hand, it has also been argued that the ASI contains a number of problematic items [11]. A reanalysis of previous studies showed that an 11-item ASI, with only 2 subscales, might be a more precise index of AS [11].

As every clinician knows, common catastrophic cognitions of patients with panic disorder include more than two or three themes, e.g. fear of heart failure, suffocation fear, fear of losing control, fear of fainting, or fear of acting ridiculous. Furthermore, as noted above, some patients believe that their symptoms cause future damage. Considering the importance of the concept of AS for cognitive theory, the number and nature of first-order AS dimensions is not trivial. It would be interesting, for instance, to see whether different AS profiles exist for patients who present at a cardiology department with atypical chest pain, patients who are seen by neurologists for unexplainable dizziness, and patients who consult pulmonologists because of attacks of breathlessness. Since only a small minority of these patients have DSM-IV panic disorder [12-15], these populations may constitute examples of single-dimensional AS elevations.

In an attempt to measure 6 dimensions of AS, Taylor and Cox [16] created a new measure, the 60-item Anxiety Sensitivity Profile (ASP). When filling out this questionnaire, subjects are asked to imagine experiencing each of 60 bodily sensations (e.g. palpitations), and then rate on a scale from 1 to 7 the likelihood that this sensation 'will lead to something bad happening to you'. The ASP was designed to measure the following 6 dimensions: fear of cardiovascular symptoms; respiratory symptoms; gastrointestinal symptoms; neurological/dissociative symptoms; publicly observable anxiety symptoms, and cognitive dyscontrol. However, a factor-analytic study with 349 college students revealed 4 dimensions, and 1 secondorder general dimension of AS [16]. The 4 dimensions were fear of (1) respiratory symptoms, (2) cognitive dyscontrol, (3) gastrointestinal symptoms, and (4) cardiac symptoms. Note that in comparison with the ASI factors [9], 'physical concerns' split into 3 dimensions, whereas there is no dimension 'social concerns'. The appropriateness of this 4-dimensional model is questionable, however, since the eigenvalue plot indicated a 1- or 2-dimensional structure (the first 3 eigenvalues were 24.0, 4.7, and 2.4).

These results seem to suggest that the ASP may be a useful alternative measure of AS, but a college student sample has serious limitations. It is a highly selective sample, particularly as regards the restricted range of age and education and the expected range of ASP scores. Indeed, the ASP item distributions were so skewed that they had to be log-transformed before further analysis [16]. A replication of this study in a more diverse population seems warranted before making any conclusions regarding the number of dimensions of the ASP. The primary aim of the present study was to investigate the factor structure of the ASP in two large samples: (1) a representative sample of the normal population, and (2) consecutive psychiatric outpatient admissions.

Relatively little is known about the relationship between AS and personality, with the exception of trait anxiety. Consensus has emerged that AS is related, but not reducible, to trait anxiety [17]. As regards other personality factors, AS measures were moderately correlated with neuroticism in a study with 94 outpatients [18]. In another study [19], the correlation between AS and negative emotionality was $r=0.40$. Negative emotionality, the tendency to experience negative affects, is a concept related to neuroticism. Two small studies have examined the 
relationship between AS and Cloningers psychobiological system of personality [20,21]. AS was moderately correlated with harm avoidance, although the sample sizes were so small that correlations fell short of significance. Harm avoidance measures sensitivity to danger, and is related to behavioral inhibition [22, 23]. The second aim of the present study was to investigate the relationship between AS, Cloningers personality dimensions and anxiety and depression in both clinical and nonclinical samples.

\section{Method}

\section{Participants and Procedure}

A normal sample consisted of individuals who were randomly selected from the telephone directory, while care was taken to select a representative proportion of people from urban and rural areas. A total of 617 individuals received a telephone call and agreed to participate. Of these, $485(78.6 \%)$ returned the questionnaires that were sent to them by mail.

A clinical sample consisted of 289 consecutive referrals to an outpatient clinic of a psychiatric hospital $(\mathrm{n}=106)$ and a regional ambulatory mental health center $(\mathrm{n}=183)$. Both facilities primarily admit patients with neurotic disorders; psychotic patients are referred to other locations of these facilities. At both outpatient facilities, patients were asked to fill out questionnaires at the time of the intake procedure. It was pointed out to patients that the data were gathered for research purposes, and informed consent was obtained.

\section{Questionnaires}

Anxiety Sensitivity. The ASP [16] was translated into Dutch, and the translation was translated back into English by a native English professional translator. No changes in meaning between the original and back-translated items were found.

Symptoms. Current (past week) levels of anxiety and depression were measured with the 14-item self-report Hospital Anxiety and Depression Scale [24]. An authorized translation and very large norm groups are available for this measure [25].

Personality. The Temperament and Character Inventory (TCI) [26-28], which is the successor of the Tridimensional Personality Questionnaire, assesses 4 dimensions of temperament (novelty seeking, harm avoidance, reward dependence, and persistence) and 3 character dimensions (self-directedness, cooperativeness, and selftranscendence). In one of the patient samples (regional mental health center), the original 240 -item TCI was administered. In the other patient sample and in the normal sample, an authorized short version ( 105 items) of the TCI was used, which correlates highly with the full-length version [29]. To enable combined data analysis, the TCI dimensions were calculated on the basis of the 105 items included in both versions in each of the samples [28].

Data Analysis

Exploratory Factor Analysis. The dimensional structure of the ASP was evaluated with Simultaneous Component Analysis (SCA) [30-32] on the correlation matrix of the 60 items of the ASP. The number of factors was determined on the basis of the sizes of the eigenvalues and the scree test [33]. SCA differs from Principal Components Analysis (PCA) in that identical components are defined which optimally account for the variance in several populations simultaneously. When a measure is administered in more than one population (e.g. patients, normals), or repeatedly in the same population, separate PCAs will not usually yield identical factors. A congruence coefficient can then be calculated. However, when the factors are clearly different in each population, this becomes difficult to interpret. Furthermore, even if the factors are clearly different, it may still be possible that very similar solutions could be found across populations, but that they simply did not appear in separate PCAs [32]. In SCA, component weights are defined as in PCA. The appropriateness of the resulting factor solution is evaluated in a similar way as in confirmatory PCA: comparing the amount of variance explained by the components of the SCA with the variance explained by separate exploratory PCAs; evaluating the correlation of items with the corresponding components (loadings), and examining the correlations among components and the correlations between components and other variables for each population [32].

Confirmatory Factor Analysis. The percentage of explained variance was subsequently compared with the amount of variance accounted for by the 6 dimensions originally proposed by Taylor and Cox [16] by means of a Multiple Group Method Analysis (MGM) [34], i.e. a matrix with binary elements only, such that each variable has a weight of one on one component and zero on the other components. MGM analysis was followed by a varimax rotation of weights, followed by oblique transformation. This rotation procedure yields optimal results in those cases where it is unlikely that an orthogonal component structure will be detected [32]. The appropriateness of the resulting factor solution was indicated by the following: (a) the variance accounted for by the a priori matrix in comparison with the variance accounted for by exploratory (6-factor solution) PCAs in both samples separately, and (b) the number of subscales well accounted for, as evidenced by the substantial correlation $(>0.40)$ of each item with the presupposed corresponding component in each sample.

The relationships among the ASP and personality dimensions were investigated using Pearson correlations. Also, partial correlations were calculated to control for current levels of anxiety and depression.

\section{Results}

\section{Preliminary Analyses}

Prior to analysis, data were screened for accuracy of data entry, missing values, normality of distribution and the presence of outliers [35]. Nineteen patients and 13 normal participants with more than 4 missing ASP items were excluded from analysis ( $4.1 \%$ of all cases). Sixty-one cases had 1 missing item, 25 cases had 2 or 3,1 case had 4 . These cases were retained; the missing values were replaced with the mean for all cases. Normality of distributions for each ASP item was examined by calculating skewness and kurtosis. Sixteen of the 60 items had either skewness or kurtosis above 1 or below -1 . However, the 
Table 1. Description of the samples

\begin{tabular}{|c|c|c|c|c|c|c|}
\hline & $\mathrm{n}$ & $\begin{array}{l}\text { Women } \\
\%\end{array}$ & $\begin{array}{l}\text { Age } \\
\text { years }\end{array}$ & $\begin{array}{l}\text { Educa- } \\
\text { tion }\end{array}$ & Anxiety & $\begin{array}{l}\text { Depres- } \\
\text { sion }\end{array}$ \\
\hline $\begin{array}{l}\text { Normal sample } \\
\text { Patient samples }\end{array}$ & 472 & 57.0 & $45.5(15.2)$ & $1.9(0.8)$ & $5.7(3.8)$ & $3.9(3.3)$ \\
\hline Outpatient clinic & 95 & 62.1 & $36.0(12.4)$ & $1.6(0.7)$ & $11.8(4.2)$ & $9.6(4.8)$ \\
\hline Mental health center & 175 & 59.4 & $37.0(9.7)$ & $1.5(0.7)$ & $12.3(4.8)$ & $9.9(5.0)$ \\
\hline
\end{tabular}

deviations were small. Square root and $\log$ transformation were both examined, but this made matters worse. It was therefore decided to use untransformed scores. The KMO index of sampling adequacy was 0.98 , which means that the correlation matrix was quite suitable for factor analysis.

\section{Participants}

A description of both samples is shown in table 1. The two patient samples did not differ on any variable and were subsequently treated as one sample. In the combined patient sample, the ASP mean total score was 195.9 (SD = 74.4), whereas the normal sample had a mean score of 153.1 (SD = 61.3). Taylor and Cox [16] did not provide mean scores for their college student sample.

\section{Exploratory Factor Analysis}

There were 7 components with eigenvalue greater than 1 in the normal sample, and 8 such components in the patient sample. In the normal sample, the first 7 eigenvalues were $25.9,5.4,2.3,1.9,1.5,1.2$ and 1.0. In the patient sample, these values were almost identical. The scree criterion indicated a 1- or 2-factor solution. The 2factor solution was inspected. These two factors explained $51.9 \%$ variance, compared with $52.0 \%$ for two separate PCAs in each sample. The factors were highly correlated: $r=0.67$ in the normal sample, and $r=0.68$ in the patient sample. Furthermore, each of the 60 items had high loadings on both factors, suggesting that the solution was overextracted.

\section{Confirmatory Factor Analysis}

Using MGM analysis, the six 10-item scales that Taylor and Cox [16] had intended for the ASP were evaluated. In terms of explained variance, these a priori scales did rather well: $61.7 \%$ (average over two samples) as compared with $63.9 \%$ for 6 -factor PCA solutions. The correla- tions among the scales were high, and varied from $r=0.58$ to $r=0.84$ in the normal sample, and from $r=0.52$ to $r=$ 0.82 in the patient sample. With almost no exceptions, the loadings were highest on the correct scale (i.e., each item had the highest correlation with the scale that it belongs to according to Taylor and Cox [16]). However, without any exception, each item also had high loadings on the other 5 scales, in both samples (all loadings $>0.27$ and typically $>0.45$ ). Cronbach's alpha was higher than 0.88 for each factor.

\section{Second-Order Factor Analysis}

The 6 Taylor and Cox dimensions were subjected to a second-order exploratory factor analysis: SCA was used to define the optimal solution for both samples. PCA on the combined samples $(n=742)$ was also carried out. The results of both analyses were almost identical and clearly yielded a 1-factor solution. In PCA, the first 3 eigenvalues were $4.6,0.6$ and 0.3 . The single factor explained $76 \%$ of the variance.

\section{Closer Assessment of the 6-Factor Solution}

Looking over the 10 items that make up each of the 6 subscales, it becomes apparent that some are almost identical. For instance, the following 3 items belong to the 'fear of respiratory symptoms' scale: (1) you feel like you're not getting enough air; (2) you feel like you can't breathe properly, and (3) you feel out of breath even though you haven't been exerting yourself. The following 3 are part of the same scale: (4) you feel like something is stuck in your throat; (5) you feel like you're choking, and (6) you have difficulty swallowing. It is unsurprising that this subscale has high internal consistency. Indeed, a factor consisting of these items may be regarded as a semantic cluster with little psychological significance. Therefore, a considerably shortened version of the ASP was also evaluated. Because all items had high intercorrelations, 
this version was created by simply taking the first 4 items of each subscale, leading to a 24-item scale. Each of the 6 shortened subscales had very high correlations with its full-length version (range: $r=0.92$ to $r=0.95$ ). The internal consistencies (Cronbach's alpha) of the 4-item scales were good (range: $0.79-0.88$ ). The short ASP consists of items 1-19, 21-24 and 27 of the 60-item ASP [16].

\section{Relationships between AS, Symptoms and Personality}

The correlations between AS and symptoms and personality are depicted in table 2 . In both samples, moderately strong correlations exist between AS and anxiety, depression and harm avoidance. A negative correlation exists between AS and self-directedness. The correlations of the 6 ASP dimensions with personality and symptoms were also calculated; the pattern was not different from that of the ASP total score. All dimensions correlated higher with anxiety (around $r=0.35$ ) than with depression (around $r=0.25$ ); there were no specifically strong correlations of any of the 6 dimensions with either anxiety or depression.

After controlling for current levels of anxiety and depression, the partial correlations between AS and harm avoidance remained significant, but dropped to $r=0.13$ $(p<0.05)$ in the clinical sample, and $r=0.17(p<0.001)$ in the normal sample. Partial correlations with selfdirectedness were nonsignificant.

\section{Discussion}

A number of different criteria exists to determine the number of factors to be extracted in a factor analysis, e.g. the number of eigenvalues greater than 1 [36], the scree test [33], and interpretability [37]. The scree test clearly suggested a 1-factor solution for the ASP. Since the extraction of more than 1 factor resulted in highly correlated factors, it seems safe to conclude that the ASP is 1-dimensional. Nevertheless, there may be circumstances in which it is useful to distinguish the 6 dimensions as originally proposed by Taylor and Cox [16]. Confirmatory factor analysis showed that this solution is defendable, despite the high intercorrelations among factors. As argued above, certain general hospital patients may have elevated scores on 1 specific dimension of AS, so the ASP may be useful in these populations.

It is also clear, however, that the ASP can be shortened considerably. Compared with the ASI, Taylor and Cox [16] introduced two changes. Firstly, the instructions and wording of items were changed: instead of conditional
Table 2. Correlations of AS with personality and symptoms

\begin{tabular}{lll}
\hline & \multicolumn{2}{l}{ ASP total score } \\
\cline { 2 - 3 } & $\begin{array}{l}\text { normal sample } \\
(\mathrm{n}=472)\end{array}$ & $\begin{array}{l}\text { patient sample } \\
(\mathrm{n}=270)\end{array}$ \\
\hline Temperament & & \\
Novelty seeking & -0.07 & 0.02 \\
Harm avoidance & $0.36^{* *}$ & $0.32^{* *}$ \\
Reward dependence & 0.11 & -0.04 \\
Persistence & 0.02 & -0.09 \\
Character & & \\
Self-directedness & $-0.24^{* *}$ & $-0.35^{* *}$ \\
Cooperativeness & -0.04 & 0.01 \\
Self-trancendence & 0.09 & $0.16^{*}$ \\
Symptoms & & \\
Anxiety & $0.42^{* *}$ & $0.55^{* *}$ \\
Depression & $0.24^{* *}$ & $0.41^{* *}$ \\
\hline
\end{tabular}

Two-tailed significance: ${ }^{*} \mathrm{p}<0.05 ;{ }^{* *} \mathrm{p}<0.001$.

wordings ('it scares me when ...'), participants are asked to imagine experiencing a sensation and then rate the probability that this 'will lead to something bad happening to me'. Secondly, the number of items was increased drastically from 16 to 60 . Our results show that the scale can be reduced to 24 items, without damage to both the contents and the reliabilities of the subscales (very high correlations between shortened and full-length versions, and high internal consistencies).

The significant correlations of AS with harm avoidance corroborate comparable findings with the ASI, which had been obtained in small samples and were therefore not statistically significant $[20,21]$. The fact that the previously reported correlations of harm avoidance with the ASI and the present correlations with the ASP were of the same magnitude provides some indirect support for the position that the ASP is an alternative measure of AS. On the other hand, 1 of the dimensions of the ASI, fear of losing cognitive control, has been found to be specifically related to depression [38-40], which was not the case in the present study with the ASP. Of course, the (shortened) ASP and the ASI should be compared directly in a single study. The usefulness of a shortened ASP may further be evaluated by investigating (a) general hospital patients with specific anxieties, e.g. cardiac phobia, and (b) the predictive power of ASP scores in different challenge paradigms. Other areas of future research include the relationship of AS and locus of control orientation [41] and the so-called causal catastrophical misinterpretations as assessed during cognitive therapy [42]. 


\section{References}

1 Reiss S, McNally RJ: The expectancy model of fear; in Reiss S, Bootzin R (eds): Theoretical Issues in Behavior Therapy. New York, Academic Press, 1985, pp 107-121.

2 McNally RJ: Panic Disorder. A Critical Analysis. New York, Guilford, 1994

3 Peterson RA, Reiss S: Anxiety Sensitivity Index Manual, ed 2. Worthington, IDS, 1992.

4 Taylor S, Koch WJ, McNally RJ: How does anxiety sensitivity vary across the anxiety disorders? J Anx Disord 1992;6:249-259.

5 Schmidt NB, Lerew DR, Jackson RJ: The role of anxiety sensitivity in the pathogenesis of panic: Prospective evaluation of spontaneous panic attacks during acute stress. J Abnorm Psychol 1997;106:355-364.

6 Schmidt NB, Lerew DR, Jackson RJ: Prospective evaluation of anxiety sensitivity in the pathogenesis of panic: Replication and extension. J Abnorm Psychol 1999;108;532-537.

7 Lilienfeld SO, Turner SM, Jacob RG: Anxiety sensitivity: An examination of theoretical and methodological issues. Adv Behav Res Ther 1993;15:147-183.

8 McNally RJ: Anxiety sensitivity is distinguishable from trait anxiety; in Rapee RM (ed): Current Controversies in the Anxiety Disorders. New York, Guilford, 1996, pp 214-227.

9 Zinbarg RE, Mohlman J, Hong NH: Dimensions of anxiety sensitivity; in Taylor S (ed): Anxiety Sensitivity. Mahwah, Erlbaum, 1999, pp 83-114.

10 Cox BJ, Parker JDA, Swinson RP: Anxiety sensitivity: Confirmatory evidence for a multidimensional construct. Behav Res Ther 1996;34 591-598.

11 Blais MA, Otto MW, Zucker BG, McNally RJ, Schmidt NB, Fava M, Pollack MH: The anxiety sensitivity index: Item analysis and suggestions for refinement. J Pers Assess 2001;77: 272-294.

12 Pollack MH, Kradin R, Otto MW, Worthington J, Gould R, Sabatino SA, Rosenbaum JF: Prevalence of panic in patients referred for pulmonary function testing at a major medical center. Am J Psychiatry 1996;153:110-113.

13 Worthington JJ, Pollack MH, Otto MW, Gould RA, Sabatino SA, Goldman L, Rosenbaum JF, Lee TH: Panic disorder in emergency ward patients with chest pain. J Nerv Ment Dis 1997;185:274-276.

14 Van Peski-Oosterbaan AS, Spinhoven P, Van der Does AJW, Willems LNA, Sterk PJ: Is there a specific relationship between asthma and panic disorder? Behav Res Ther 1996;34: 333-340
15 Van Peski-Oosterbaan AS, Spinhoven P, Van der Does AJW, Bruschke AVG, Rooijmans HGM: Cognitive change following cognitive behavioural therapy for non-cardiac chest pain. Psychother Psychosom 1999;68:214-220.

16 Taylor S, Cox BJ: Anxiety sensitivity: Multiple dimensions and hierarchic structure. Behav Res Ther 1998;36:37-51.

17 Lilienfeld SO: Anxiety sensitivity and the structure of personality; in Taylor S (ed): Anxiety Sensitivity. Mahwah, Erlbaum, 1999, pp 149-180.

18 Arrindell WA: The fear of fear concept: Evidence in favour of multidimensionality. Behav Res Ther 1993;31:507-518.

19 Lilienfeld SO: The relation of anxiety sensitivity to higher and lower order personality dimensions. J Abnorm Psychol 1997;106:539-544.

20 Saviotti FM, Grandi S, Savron G, Ermentini R, Bartolucci G, Conti S, Fava GA: Characterological traits of recovered patients with panic disorder and agoraphobia. J Affect Disord 1991;23:113-117.

21 Fava GA, Grandi S, Belluardo P, Savron G, Raffi AR, Conti S, Saviotti FM: Benzodiazepines and anxiety sensitivity in panic disorder. Prog Neuropsychopharmacol Biol Psychiatry 1994;18:1163-1168.

22 Gray JA: The Neuropsychology of Anxiety. New York, Oxford University Press, 1982.

23 Carver CS, White TL: Behavioral inhibition, behavioral activation, and affective responses to impending reward and punishment: the BIS/ BAS scales. J Pers Soc Psychol 1994;67:319333.

24 Zigmond AS, Snaith RP: The Hospital Anxiety and Depression Scale. Acta Psychiatr Scand 1983;67:361-370.

25 Spinhoven P, Ormel J, Sloekers PPA, Kempen GIJM, Speckens AEM, Van Hemert AM: A validation study of the Hospital Anxiety and Depression Scale (HADS) in different groups of Dutch subjects. Psychol Med 1997;27:363370 .

26 Cloninger CR, Przybeck TR, Svrakic DM, Wetzel RD: The Temperament and Character Inventory (TCI): A Guide to Its Development and Use. St Louis, Center for the Psychobiology of Personality, 1994.

27 De la Rie S, Duijsens IJ, Cloninger CR: Temperament, character and personality disorders. J Pers Disord 1998;12:362-372.
28 Duijsens IJ, Spinhoven P, Goekoop JG, Spermon A, Eurelings-Bontekoe EHM: The Dutch Temperament and Character Inventory (TCI) Dimensional structure, reliability and validity in a normal and psychiatric outpatient sample. Pers Ind Differ 2000;28:487-499.

29 Duijsens IJ, Spinhoven P, Verschuur M, Eurelings-Bontekoe EHM: De Nederlandse Verkorte Temperament en Karakterschaal (VTCI). Ned Tijdschr Psychol 1999;54:276-283.

30 Millsap RE, Meredith W: Component analysis in cross-sectional and longitudinal data. Psychometrika 1988;53:123-134.

31 Kiers HAL, Ten Berge JMF: Alternating least squares algorithms for simultaneous components analysis with equal component weight matrices in two or more populations. Psychometrika 1989;54:467-473.

32 Kiers HAL: SCA User's Manual. A Program for Simultaneous Components Analysis of Variables Measured in Two or More Populations. Groningen, ProGamma, 1990.

33 Cattell RB: The scree test for the number of factors. Multivar Behav Res 1966;1:245-276.

34 Nunnally J: Psychometric Theory. New York, McGraw-Hill, 1978.

35 Tabachnick BG, Fidell LS: Using Multivariate Statistics, ed 2. New York, Harper Collins, 1989.

36 Kaiser H: A note on Guttman's lower bound for the number of common factors. Multivar Behav Res 1961;1:249-276.

37 Gorusch R: Factor Analysis. Hillsdale, Erlbaum, 1983.

38 Otto MW, Pollack MH, Fava M, Uccello R. Rosenbaum JF: Elevated anxiety sensitivity scores in patients with major depression: Correlates and changes with antidepressant treatment. J Anx Disord 1995;9:117-123.

39 Taylor S, Koch WJ, Woody S, McLean P: Anxiety sensitivity and depression: How are they related? J Abnorm Psychol 1996;105:474-479.

40 Schmidt NB, Lerew DR, Joiner TE: Anxiety sensitivity and the pathogenesis of anxiety and depression: Evidence for symptom specificity. Behav Res Ther 1998;36:165-177.

41 Bakker A, Spinhoven P, Van der Does AJW, Van Balkom AJLM, Van Dyck R: Locus of control orientation in panic disorder and the differential effects of treatment. Psychother Psychosom 2002;71:85-89.

42 Bakker A, Spinhoven P, Van Balkom AJLM Van Dyck R: Relevance of assessment of cognitions during panic attacks in the treatment of panic disorder. Psychother Psychosom 2002: $71: 158-161$ 